the more rigorous terms employed here gain general currency. Some experimental domestications, of moose, muskoxen and musk deer, are considered in the next section. The moose has been tamed, if not domesticated, for so long that its management is hardly experimental. Muskoxen are kept largely for the production of qiviut, which is the fine underwool. The final section considers the environmental and socio-economic aspects of exploitation, an area that is frequently overlooked in many texts on wildlife utilization.

The competence and experience of the authors gives one confidence in the reliability of the text. They can also write well so that the book may be read for pleasure as well as profit. It should appeal to a wide audience, from practical wildlife managers to academics, and I expect it to remain a useful reference book for many years, although it would have been easier to handle if all the references had been gathered together in the back instead of being dispersed at the end of the chapters. S. K. Eltringham.

Wildlife Management in SubSaharan Africa: Sustainable Economic Benefits and Contribution Towards Rural Development

International Foundation for the Conservation of Game

IGF Paris, 727 pp., PB 250FF or \$US45 from CIC, 15 Rue de Téhéran, F-75008, Paris

This book is a bibliographer's nightmare. There is no date of publication, no ISBN number and no apparent publisher, although the address of the IGF is listed on the back cover. There appears not to have been an editor, an omission that is readily obvious from the chaotic arrangement of the contents. There is not even an introduction explaining what the book is about and one has to search through the pages to discover that it is in fact the proceedings of an international conference, or rather of two conferences, for a 'High-level Conference' was held immediately after what was presumably a lowlevel one. The meetings took place in Harare, Zimbabwe, between 6 and 12 October 1987. Much of the proceedings are reproduced verbatim, complete with the circumlocutions inherent in welcoming speeches. The discussion at the end of some papers is also given, sometimes in an incoherent fashion with the answers but not the questions to which they are addressed. The individual papers are printed as they were sent in by the authors so that the presentation varies from photocopies of print quality to all sizes of type. One paper has been printed with a reviewer's comments pencilled in the margins. Most of the text is in English but some papers are in French and some in both languages. English-only papers have French summaries and vice versa. The book has an attractive, coloured cover but it is flimsily produced and most of the pages fell out of the front of my copy as soon as they were turned. Page 719, which should have listed some of the participants, is blank.

The book, therefore, leaves a lot to be desired physically and in organization but what of its contents? As is so frequently the case with conference reports, it is a mixture of the good and the ephemeral. Its principal virtue is that it gathers together a wealth of information on wildlife utilization that would either have not been published or which would have been scattered throughout a diversity of journals. It is not easy to extract the nuggets from the present book, for it has no index, although there is a comprehensive table of contents. Had it been more rigorously edited to eliminate the trivia and more professionally produced, it would have had a much bigger impact on conservation thinking. As it is, I suspect that it will be overlooked by people who would benefit from reading it. S. K. Eltringham.

\section{The Great Migration}

Jonathan Scott Elm Tree Books, London, 1988, 159 pp., HB $€ 25.00$

This book describes, in words and pictures, the migrations of the wildebeest and zebra in the Serengeti ecosystem, i.e. the Serengeti National Park, much of the Ngorongoro Conservation Area and the surrounding game reserves, including the Masai Mara National Reserve in Kenya. The photography is suberb and has deepened my inferiority complex over cameras. It is not simply a question of technical excellence for the author has succeeded in capturing on film, dramatic and rare events on the plains. The pictures are vibrant with life so that one can hear the swish of the wildebeest's tail and smell the dust kicked up by their hooves. The reproduction of the photographs is excellent although it is unfortunate that so many of them extend on to another page. This is acceptable with double-page spreads but the presentation loses something when part of the picture is divided off by the central fold.

The book will, no doubt, be purchased primarily for the pictures but it will be a pity if 